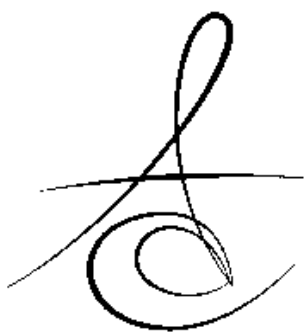

\title{
KİTOSAN TAŞIYICILI BEYAZLATMA AJANININ DİŞ RENK DEĞİŞİMİNE ETKİsi
}

\section{EFFECT OF BLEACHING AGENT INCORPORATED CHITOSAN ON TOOTH COLOR CHANGE}

\author{
Dr. Öğr. Üyesi Samet TOSUN*
}

Makale Kodu/Article code: 3364

Makale Gönderilme tarihi: 16.02.2017

Kabul Tarihi: 18.08.2017

\section{öz}

Amaç: Bu in vitro çalışmanın amacı; farklı konsantrasyonlara sahip kitosan taşıyıcı içerikli beyazlatma ajanlarının beyazlatma etkinliklerinin incelenmesidir.

Gereç ve Yöntem: Çalışmada kullanılan çekilmiş 30 adet A3 ve daha yukarı renge sahip anterior dişi rastgele 3 gruba ayrıldı. Grup 1; karbopol içerikli ticari bir ürün Whiteness Super Endo, Grup 2; Kitosan taşıyıcı içerikli \%37 karbamid peroksit, Grup 3; Kitosan taşıyıcı içerikli \%16 karbamid peroksit. Kök kanal perepasyonları yapıldıktan sonra dolduruldu. Mine semet sınırdan $2 \mathrm{~mm}$ aşağıda olacak şekilde gutta perka kesildi. Yaklaşık $2 \mathrm{~mm}$ kalınlıkta cam iyonomer siman yerleştirildi. Beyazlatma ajanı 3-4 gün arayla 3 kez tekrarlandı. Spektrofotometre cihazı ile beyazlatma etkinlikleri ölçüldü. Grupların karşılaştırılmasında tek yönlü varyans analizi ve Tukey HSD testleri, kullanıldı (a =0.05).

Bulgular: Spektrofotometre analizi sonuçlarına göre beyazlatma etkinlikleri açısından bütün gruplar arasında anlamlı bir farkılık gözlenmedi. Farklı konsantrasyonu denenen Kitosan içerikli beyazlatma ajanlarının beyazlatma etkinlikleri benzer bulundu. $(p>0.05)$

Sonuç: Bu in vitro test koşulları altında kitosan, beyazlatma ajanın içerisinde alternatif bir taşıyıcı olarak kullanılabilir.

Anahtar Kelimeler: Diş beyazlatma, kitosan, karbamid peroksit

\section{ABSTRACT}

Aim: The aim of this in vitro study was to compare the bleaching efficacy of different concentrations of bleaching agents containing chitosan delivery system.

Materials and Methods: Thirty extracted maxillary incisors tooth which colour with A3 or over, randomly divided into 3 test groups; Group 1 was carpobol with Whiteness Super Endo (\%37 carbamid perxoide) Group 2 was chitosan with \%37 carbamid peroxide, Group 3 was chitosan with \%16 carbamid peroxide. After finishing canal preparation and root canal filling, the root fillings were removed to a level $2 \mathrm{~mm}$ apical to the cementoenamel junction. Glass ionomer base was placed approximately 2-mm thick. Bleaching agents was placed into the rest of the cavity for 3-4 days at 3 times. Bleaching efficiency was measured a spectrophotometer. Groups were compared by using one way analysis of variance (ANOVA) and Tukey's HSD post hoc tests ( $\alpha=0.05)$.

Results: According to the spectrophotometer analysis, statistically no significant color changes were found in all groups. Bleachings agents containing chitosan were similar whitening effeciency. $(p>0.05)$.

Conclusion: According to the results of this in vitro study it can be concluded that chitosan, bleaching, can be used as an alternative carrier.

Keywords: Teeth bleaching, chitosan, carbamid peroxide

* Pamukkale Üniversitesi Diş Hekimliği Fakültesi, Endodonti A.D. Denizli. 


\section{GİRİş}

Estetik kaygıların giderek arttığı günümüzde, diş renklenmelerinin tedavi edilmesi büyük önem taşımaktadır. Endodontide lokal etkenlere bağlı olarak renklenmiş dişlerin kök kanal tedavisini takiben intrakoroner yöntem ile beyazlatılması işlemi diş hekimlerinin güncel uygulamalardandır. ${ }^{1,} 2$ Diş hekimliğin de beyazlatma için daha çok, hidrojen peroksit, karbamid peroksit ve türevlerini içeren ürünler kullanılmaktadır. ${ }^{3}$

Uygulama sıklığını azaltmak ve lokal olarak mine ve dentin üzerindeki etkiyi artırmak amacıyla beyazlatma ajanlarını taşıyıcı sisteme yükleyerek uygulamak mümkündür. Taşıyıcı sistemlerde genel olarak doğal ve sentetik materyaller kullanılmaktadır. ${ }^{4-6}$ Günümüzde beyazlatma ajanlarının içerisinde en çok kullanılan taşıyıcı sistem karbopoldür. Bu taşıyıcı sistemler arasında kitosan da bulunmaktadır, kabuklu deniz hayvanlarından elde edilen kitinin yüksek alkali ortamda kısmi deasetilasyonu ile hazırlanan katyonik özellikte doğal bir polimer yapısındadır. Biyoadezif, biyoparçalanır, biyouyumlu özelliklerinin yanı sıra, antifungal, antimikrobiyal, hemostatik ve biyoaktif özelliklere sahiptir. Kitosan, diş hekimliğinde birçok araştırmaya konu olmuştur ${ }^{7-12}$.

$\mathrm{Bu}$ in vitro çalışmanın amacı, dişlerin beyazlatılmasında karbamid peroksit'in daha uzun aktivasyonunu sağlayabilmek ve aynı zamanda beyazlatmada kullanılan karbamid peroksit konsantrasyonunun azaltılması için Kitosan'nın taşıyıcı olarak kullanılmasıdır. Bu çalışmada, endodontik tedavi görmüş dişlerin intrakoronal beyazlatmasında rutin olarak kullanılmakta olan karbamid peroksit içerikli beyazlatma ajanı ile yeni geliştirilen farklı konsantrasyonlardaki karbamid peroksit içeren kitosan taşıyıcılı beyazlatma ajanlarının diş üzerinde meydana getirdikleri beyazlatma etkinliklerinin spektrofotometrik analiz yöntemiyle karşılaştırılması incelenmektedir.

\section{GEREÇ VE YÖNTEM}

In vitro çalışma için Gaziantep Üniversitesi Klinik Araştırmalar Etik Kurulundan onay alındı (Karar no: 2016/113). Çalışmada yeni çekilmiş, A3 ve üzeri renge sahip 30 adet üst ön kesici, santral ve lateral insan dişi kullanıldı. Çalışmaya dahil edilecek dişlerin seçilirken kırık, çürük, çatlak olmamasına dikkat edildi. Dişlerin kök yüzeyindeki sert ve yumuşak doku artıkları bir bisturi yardımı ile uzaklaştırıldı. Dişler kullanılacakları zamana kadar, herhangi bir koruyucu kullanımadan, buzdolabında $+4 \mathrm{C}^{\circ}$ de, serum fizyolojik içinde saklandı. Endodontik giriş kavitesi ISO (International Organisation of Standardization) 12 elmas rond frez (Diatech, Coltene Whaledent, Altststten, Switzerland) kullanılarak su soğutması altında açıldı. Kanal girişinin belirlenmesinden sonra, Kök kanalı şekillendirme işlemi; protaper döner sistemleri (DentsplyMaillefer,Ballaigues,Switzerland) ile yapıldı. Kanallara kurulandıktan sonra AH 26 pat (Dentsply, De Trey, Konstanz, Germany) ve gutta perka (SPI Dental, Inchon, Korea) kullanılarak soğuk lateral kondenzasyon tekniği ile dolduruldu. Sonra doldurulan kanalların mine-sement birleşiminin $2 \mathrm{~mm}$ apikalinden gutta perka kesildi. İyonomer siman (Vitrabond, 3M Dental Products, St Paul, Minn) ile 2 mm kalınlıkta olacak şekilde kanal ağızları kapatıldı. Dişler rastgele her grupta 10 diş olacak şekilde 3 gruba ayrıldı. Grup 1 için ticari bir ürün olarak Whiteness super- Endo (FMG, Joinville, SC Brasil) seçildi. \% 3'lük kitosan elde etmek için elimizdeki toz kitosan (Sigma Aldrich Co, St. Louis, Missouri, ABD), \% 1'lik sitrik asit (Pozitif Kimya, Pozitif Kimya Pazarlama ve Ticaret A.Ş., Tuzla, Türkiye) çözeltisinde iki saat boyunca manyetik karıştırıcıda (İsotex Magnetic Stirrer SH-3, Pekin, Çin Halk Cumhuriyeti) karıştırılarak elde edildi. Daha sonra \% 16 ve $\%$ 35'lik karbamid peroksit solüsyonu hazırlamak için elimizdeki toz karbamid peroksitten (Merck KgaA, Germany EMD Milipore Corporation, ABD) 3,2 ve $7 \mathrm{gr}$ karbamid peroksit hassas terazi (Acculab ALC Series Precision Balances, Sartorius Group, Arvada/Colorado, $A B D$ ) ile ölçüldü, ardından 5'er ml gliserin eklenerek grup 2 ve 3 hazırlandı. Hazırlanan karbamid peroksitler $5 \mathrm{ml}$ kitosan çözeltisi ile karıştırılarak Tablo $1^{\prime}$ de içeriği belirtilen gruplar elde edildi. Sonrasında bütün gruplara aşağıdaki işlemler sırasıyla yapıldı. Beyazlatma uygulaması yapılmadan önce dişlerin spektrofotometre cihazı (VITA Easy Shade Advance, Zahnfabrik H.Rauter GmbH\&Co. KG, Germany) ile ilk renkleri belirlendi. Ölçüm, cihazın kullanım talimatlarına uygun olarak cihazın ucu dişin bukkal yüzeyinde orta üçlü alanın merkezine temas edecek şekilde konumlandırılarak yapıldı. Spektrofotometre her kullanımdan önce üretici firma önerileri doğrultusunda kalibre edildi. Beyazlatma ajanları pulpa odasına konuldu, üzerine pamuk pelet yerleştirildi. Geçici bir simanla kapatıldı. Üretici firmanın talimatları doğrultusunda 3-4 
günde değişecek şekilde 3 kez uygulandı. Beyazlatma işleminden sonra Filtek Ultimate (3M ESPE, St. Paul, MN, USA) kompozit dolgu ile restorasyonları yapıldı. Beyazlatma tedavisinin sonunda tekrar $L *, a *, b *$ ayrıntılı değerleri her diş için kaydedildi. Çalışma sonunda elde edilen kolorimetre verilerinin istatistiksel değerlendirilmesi; ANOVA ve Tukey HSD testleri ile yapıııışıtır.

Tablo 1. Çalışmada kullanılan beyazlatma ajanlarının içeriği

\begin{tabular}{|c|c|c|}
\hline KOD & Beyazlatma ajanları & İçerik \\
\hline $\begin{array}{l}\text { GRUP } \\
1\end{array}$ & Whiteness super- endo & $\begin{array}{l}\text { \% } 37 \text { Karbamid peroksit, } \\
\text { karbopol, gliserin }\end{array}$ \\
\hline $\begin{array}{l}\text { GRUP } \\
2\end{array}$ & $\begin{array}{l}\text { \%35 Karbamid peroksit + } \\
\% 1-3 \text { Kitosan }\end{array}$ & $\begin{array}{l}\% 35 \text { Karbamid peroksit+ } \\
\% \text { 1-3Kitosan (hacim/hacim), } \\
\% \text { 1sitrik asit, gliserin }\end{array}$ \\
\hline $\begin{array}{l}\text { GRUP } \\
3\end{array}$ & $\begin{array}{l}\% 16 \text { Karbamid peroksit + } \\
\% 1-3 \text { Kitosan }\end{array}$ & $\begin{array}{l}\% 16 \text { Karbamid peroksit+ } \\
\% \quad 1-3 \text { Kitosan (h/h), \% } 1 \\
\text { sitrik asit, gliserin }\end{array}$ \\
\hline
\end{tabular}

\section{Renk ölçümü}

Çalışmamızda dişlerde meydana gelen renk farklılıkları CIEab renk sistemindeki $L * a * b *$ değerleri ve $\Delta E 2-1=\left[(\Delta L)^{2}+(\Delta a)^{2}+(\Delta b)^{2}\right]^{1 / 2}=\left[(L 2-L 1)^{2}+\left(a^{2}-\right.\right.$ $\left.\left.a^{1}\right)^{2}+\left(b^{2}-b^{1}\right)^{2}\right]^{1 / 2}$ formülü ile hesaplanan ${ }^{13} \Delta E$ değeri kullanılarak hesaplanmıştır. $\Delta \mathrm{E}$ değeri iki ölçüm arasındaki renk farkını ifade etmektedir. Ayrıca oluşan bu renk değişikliği $(\Delta E)$, National Bureau of Standards tarafından belirlenmiş olan NBS kriterleri ve renk değişim miktarının klinik eşlemesi kullanılarak ta değerlendirildi (Tablo 2). Bu dönüşüm için kullanılan NBS değeri formülü $\Delta \mathrm{E} \times 0.92^{\prime}$ dir. $^{14}$

Tablo 2. NBS Renk Toleransı

\begin{tabular}{|l|l|}
\hline Renk farklılı̆ı & NBS değerleri \\
\hline Çok $a z$ & $0-0.5$ \\
\hline $\mathrm{Az}$ & $0.5-1.5$ \\
\hline Gözle fark edilebilir & $1.5-3.0$ \\
\hline Kayda değer & $3.0-6.0$ \\
\hline Yüksek & $6.0-12.0$ \\
\hline Çok yüksek & $12.0+$ \\
\hline
\end{tabular}

\section{BULGULAR}

Ticari ürün olan Whiteness Super - Endo (Grup 1) ile yeni geliştirilen taşıyıcı sistemler içeren beyazlatma ajanları arasında istatistiksel olarak bir farklılık bulunamadı $(p>0.05)$ (Grup 2 ile $p=0.670$, Grup 3 ile $p=0.104$ ). Farklı konsantrasyonları denenen yeni geliştirilen beyazlatma ajanlarııı arasında istatistiksel bir fark bulunamadı $(p>0.05, p=0.427)$ (Tablo 3,4). Tüm gruplarda beyazlatma öncesi ve sonrasında aldığımı fotoğraflardan elde ettiğimiz subjektif bulgulara göre fark edilebilir bir beyazlık gözlendi (Resim 1). Fakat NBS kriterleri açısından değerlendirildiğinde en iyi sonucun Grup 1'in olduğu tespit edildi.

Tablo 3. Tüm grupların $\Delta \mathrm{E}$ değişimi ortalama ve standart sapma değerleri $(\mathrm{n}: 10)$

\begin{tabular}{|c|c|}
\hline Gruplar & $\begin{array}{c}\Delta \mathrm{E}_{1} \\
\text { Ort } \pm \text { SS }\end{array}$ \\
\hline Grup 1 & $12,53 \pm 4,45$ \\
\hline Grup2 & $10,64 \pm 6,88$ \\
\hline Grup3 & $10,34 \pm 5,12$ \\
\hline
\end{tabular}

Tablo 4. Beyazlatma etkinliğinin gruplar arası çoklu kıyaslamasında elde edilen anlamlıı̆ın ikili gruplara yansımasının değerlendirilmesi

\begin{tabular}{|c|c|c|c|c|c|}
\hline Grupla & & $\begin{array}{l}\text { Mean } \\
\text { difference }\end{array}$ & $\begin{array}{l}\text { Std. } \\
\text { Error }\end{array}$ & Sig. & $\begin{array}{l}\text { Tukey } \\
\text { HSD * }\end{array}$ \\
\hline Grup 1 & $\begin{array}{l}\text { Grup2 } \\
\text { Grup3 }\end{array}$ & $\begin{array}{l}1,88938 \\
4,66792\end{array}$ & $\begin{array}{l}2,19713 \\
2,19713\end{array}$ & $\begin{array}{l}670 \\
104\end{array}$ & A \\
\hline Grup 2 & $\begin{array}{l}\text { Grup1 } \\
\text { Grup3 }\end{array}$ & $\begin{array}{l}-1,88938 \\
2,77854\end{array}$ & $\begin{array}{l}2,19713 \\
2,19713\end{array}$ & $\begin{array}{l}670 \\
, 427\end{array}$ & $A$ \\
\hline Grup 3 & $\begin{array}{l}\text { Grup1 } \\
\text { Grup3 }\end{array}$ & $\begin{array}{l}-4,66792 \\
-2,77854\end{array}$ & $\begin{array}{l}2,19713 \\
2,19713\end{array}$ & $\begin{array}{l}0,104 \\
, 427\end{array}$ & A \\
\hline
\end{tabular}

${ }^{*}$ Farklı harfler istatistiksel olarak anlamlı farklıı̆ı ifade etmektir $(p<0.05)$.

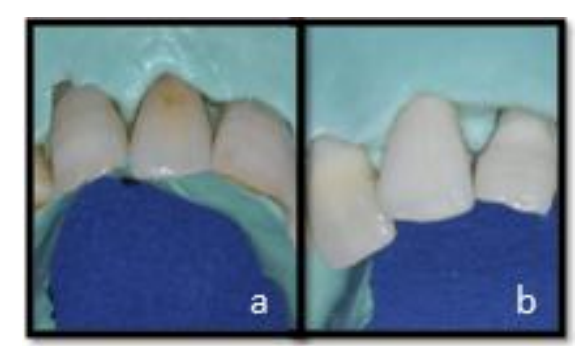

Resim 1. Dişlerin görünümü a) beyazlatma öncesi b) $\% 35$ kitosan içeren beyazlatma ajanının kullanımı sonrası

\section{TARTIŞMA}

Beyazlatma tedavisi konservatif bir uygulama olması sebebiyle hekimlerin ilk düşündüğü tedavi seçeneğidir ve diş hekimliğinde önemli bir yer tutmaktadır. Beyazlatma tedavisine ilginin artması ile birlikte beyazlatma ajanlarının oluşturdukları etkilerinin belirlenmesi amacıyla birçok araştırma yapıımıştır. ${ }^{15-17}$

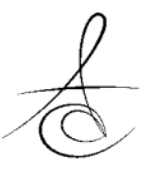


Diş hekimliğinde spektrofotometrik ölçümler; çeşitli dental materyallerin renklerinin sayısal ifadelerini bulmak ve renkli iki cismin arasındaki renk farkını değerlendirmede kullanılmaktadır. Bu konu ile yapılan bir çalş̧mada, spektrometrik cihazların görsel skalaya göre daha doğru sonuçlar verdiği belirtilmiştir. ${ }^{18}$ Spektrometrik cihaz kullanımının daha doğru ve uygulanabilir bir renk analizi yöntemi olması nedeniyle biz de bu yöntemi kullanmaya tercih ettik.

Son yillarda vital diş beyazlatmada popüler olarak kullanılan karbamid peroksit ${ }^{19-21}$, intrakoronal beyazlatmada da sıklıkla kullanılmaktadır. ${ }^{2,17}$ Beyazlatma ajanlarının içeriği incelendiğinde sıklıkla taşıyıcı sistem olarak karpobol kullanıldığı görülmektedir ${ }^{22,} 23$. Yapılan bir çalışmada karpobol polimerinin dişin demineralizasyonunu artırdığı, kalsiyumu olan afinitesi nedeni ile de hidroksi apatitleri inhibe ettiği bildirilmiştir. ${ }^{23}$ Karbopol'un bu olumsuz etkisine nazaran kitosan demineralizasyonun önlenmesinde katkıda bulunmaktadır. ${ }^{24,}{ }^{25}$ Bu özelliği de göz önüne alınarak doğal bir taşıyııı polimer olan kitosan farklı konsantrasyonlarda karbamid peroksitin içerisine eklendi ve beyazlatma etkinlikleri karpobol içeren ticari bir ürün ile karşılaştırıldı.

Yapmış olduğumuz literatür araştırmasında karbamid peroksit'in kitosan taşıııcı sistemle kombine kullanıldığına dair herhangi bir in vitro veya in vivo çalışmaya rastlanmadığından dolayı elde etmiş olduğumuz verilerin karşılaşırma imkanı bulunamamıştır. Karpobol taşıyıcı sisteme sahip ticari bir ürün ile karşılaştııılıı̆ında beyazlatma açııında kitosan taşıyıcııı gruplarla arasında anlamlı fark bulunamadı. Beyazlatma tedavisinde kullanılacak ajanın konsantrasyonu konusunda pek çok farklı görüş bulunmaktadır. Bazı araştırmacılar yüksek konsantrasyonlu beyazlatma sistemlerinin daha hızlı bir beyazlatma meydana getirse de; düşük konsantrasyonlu ajanların uzun süre kullanımı ile aynı etkinin elde edilebileceğini savunmaktadırlar. ${ }^{26,}, 27$ Matis ve ark. ${ }^{28}$ yaptıkları bir çalışmada \% 15-40 arasında hidrojen peroksit içerikli 8 farklı ofis tipi beyazlatma sistemini in vivo olarak karşısaşırmış tüm sistemlerin beyazlatma etkinliğinin benzer olduğunu bildirmişlerdir. Bizim çalışmamızda da farklı konsantrasyonda karbamid peroksit içermesine rağmen aynı sürede benzer beyazlatma değerleri bulundu. Bu durum kitosanın iyi bir taşıyıcı özelliğe sahip olmasından ve peroksitin beyazlatma etkisini azaltmamasından kaynaklanabilir. Ayrıca düşük konsantrasyon değerle- rinin mine ve çevre dokulara meydana gelebilecek olası yan etkileri azaltacağını da düşünmekteyiz. Beyazlatma verilerine göre kitosan peroksit ajanlarla uyumlu olarak kullanılabilen, yeterli viskozitede, kolay uygulanabilen, peroksit ajanların beyazlatma etkisini azaltmayan iyi bir taşıyıcı ajandır.

\section{SONUÇ}

$\mathrm{Bu}$ in vitro çalışma koşullarında, kitosan taşıyıcı sistem içeren beyazlatma ajanı, karpobol taşııııı içeren ticari bir ürün ile karşılaştıııldığında beyazlatma etkinliğinin benzer olması, ayrıca karbamid peroksitin konsantrasyonu yarıya indirilmesine rağmen beyazlatma etkinliği açısından fark olmaması kitosanın, bir beyazlatma ajanı içerinde alternatif taşıııı olarak kullanılabileceğini göstermektedir.

\section{Samet Tosun: ORCID ID: 0000-0003-3277-197X}

\section{KAYNAKLAR}

1. Timpawat S, Nipattamanon C, Kijsamanmith K, Messer $\mathrm{H}$. Effect of bleaching agents on bonding to pulp chamber dentine. Int Endod J. 2005;38:2117.

2. Ganesh R, Aruna S, Joyson M. Comparison of the bleaching efficacy of three different agents used for intracoronal bleaching of discolored primary teeth: an in vitro study. J Indian Soc Pedod Prev Dent. 2013;31:17.

3. Goldstein RE. Bleaching teeth: new materials-new role. J the Am Dent Assoc. 1987;115:44E-52E.

4. Needleman IG, Smales FC, Martin GP. An investigation of bioadhesion for periodontal and oral mucosal drug delivery. J Clin Periodontol. 1997;24:394-400.

5. Rathbone MJ, Pather I, Şenel S. Overview of Oral Mucosal Delivery. Rathbone MJ Ed. Mucosal Drug Delivery and Therapy, Advances in Delivery Science and Technology: Springer US: 2015. p. 1729.

6. Şenel S. Potential applications of chitosan in oral mucosal delivery. J Drug Deliv Sci Technol 2010;20:23-32.

7. Ikinci G, Şenel S, Akıncıbay H, Kaş S, Erciş S, Wilson $C$, et al. Effect of chitosan on a periodontal pathogen Porphyromonas gingivalis. Inter J Pharm. 2002;235:121-7. 
8. Senel S, Kas H, Squier C. Application of chitosan in dental drug delivery and therapy. Muzzarelli, Riccardo AA, ed. Chitosan per os: from dietary supplement to drug carrier Grottammare: Atec. 2000. p. 241-56.

9. Şenel S, Ikinci G, Kaş S, Yousefi-Rad A, Sargon M, Hincal A. Chitosan films and hydrogels of chlorhexidine gluconate for oral mucosal delivery. Inter J Pharmac 2000;193:197-203.

10. Fakhry A, Schneider GB, Zaharias R, Şenel S. Chitosan supports the initial attachment and spreading of osteoblasts preferentially over fibroblasts. Biomaterials 2004;25:2075-9.

11. Akıncıbay $\mathrm{H}$, Şenel S, Yetkin Ay Z. Application of chitosan gel in the treatment of chronic periodontitis. J Biomed Mater Res B Appl Biomater 2007;80:290-6.

12. Uraz A, Boynueğri D, Özcan G, Karaduman B, Uç $\mathrm{D}$, Şenel S, et al. Two percent chitosan mouthwash: A microbiological and clinical comparative study. J Dent Sci 2012;7:342-9.

13. Baltzer A, Kaufmann-Jinoian V. The determination of the tooth colors. Quintessenz Zahntech. 2004;30:726-40.

14. Kara $H$, Aykent F, Ozturk B. The effect of bleaching agents on the color stability of ceromer and porcelain restorative materials in vitro. Oper Dent 2012;38:E1-E8.

15. Li Q, Yu H, Wang Y. Colour and surface analysis of carbamide peroxide bleaching effects on the dental restorative materials in situ. J Dent 2009;37:34856.

16. Dey S, Pandey V, Kumar A, Awasthi N, Sahu A, Pujari S. In vitro Comparison of Impact of different Bleaching Agents on the microhardness of Enamel. Dent Pract 2016;17:258-62.

17. Smidt A, Feuerstein O, Topel M. Mechanical, morphologic, and chemical effects of carbamide peroxide bleaching agents on human enamel in situ. Quintessence Int 2011;42:407-12.

18. Paul S, Peter A, Pietrobon N, Hämmerle C. Visual and spectrophotometric shade analysis of human teeth. J Dent Res 2002;81:578-82.

19. Metz MJ, Cochran MA, Matis BA, Gonzalez C, Platt JA, Lund MR. Clinical evaluation of $15 \%$ carbamide peroxide on the surface microhardness and shear bond strength of human enamel. Oper Dent 2007;32:427-36.
20. Basting $R$, Rodrigues $A$, Serra $M$. The effect of $10 \%$ carbamide peroxide bleaching material on microhardness of sound and demineralized enamel and dentin in situ. Oper Dent 2001;26:531-9.

21. Yüzügüllü $B$, Çelik Ç, Erkut $S$. Karbamid Peroksit İçeren Beyazlatma Ajanının Kompozit Rezinlerin Yüzey Pürüzlülüğüne Etkisi. Atatürk Üni Diş Hek Fak Derg. 2008;3:94-8.

22. Lopes GC, Bonissoni L, Baratieri LN, Vieira LCC, Monteıro S. Effect of bleaching agents on the hardness and morphology of enamel. J Esthet Restor Dent 2002;14:24-30.

23. Basting $R$, Rodrigues $A$, Serra $M$. The effect of $10 \%$ carbamide peroxide, carbopol and/or glycerin on enamel and dentin microhardness. Oper Dent 2005;30:608.

24. Arnaud TMS, de Barros Neto B, Diniz FB. Chitosan effect on dental enamel de-remineralization: an in vitro evaluation. J Dent 2010;38:848-52.

25. Visveswaraiah PM, Prasad D, Johnson S. Chitosan A novel way to intervene in enamel demineralization-An in vitro study. Int J Curr Microbiol App Sci 2014;3:617-27.

26. Sulieman M, Addy M, MacDonald E, Rees J. The effect of hydrogen peroxide concentration on the outcome of tooth whitening: an in vitro study. J Dent 2004;32:295-9.

27. Sulieman M, Macdonald E, Addy $M$. Tooth bleaching by different concentrations of carbamide peroxide and hydrogen peroxide whitening strips: an in vitro study. J Esthet Restor Dent 2006;18:93100.

28. Matis B, Cochran M, Franco M, Al-Ammar W, Eckert G, Stropes M. Eight in-office tooth whitening systems evaluated in vivo: a pilot study. Oper Dent 2007;32:322-7.

\author{
Yazışma Adresi \\ Samet TOSUN \\ Pamukkale Üniversitesi \\ Diş Hekimliği Fakültesi , \\ Endodonti A.D., \\ Pamukkale /Denizli, Türkiye. \\ Tel: +90 (258) 2961747 \\ e-mail: samettosun06@gmail.com
}

